\title{
Atypical cardiac tamponade in severe pulmonary hypertension
}

\author{
Saraschandra Vallabhajosyula, Pranathi Rao Sundaragiri
}

Department of Internal Medicine, Creighton University School of Medicine, Omaha, Nebraska, USA

\section{Correspondence to}

Dr Saraschandra

Vallabhajosyula,

SaraschandraVallabhajosyula1 @creighton.edu

Accepted 22 February 2015

\section{DESCRIPTION}

A 33-year-old Caucasian woman with Class 1 idiopathic pulmonary arterial hypertension (PAH) managed on tadalafil, ambrisentan, treprostinil, digoxin and diuretics presented with progressive dyspnoea and orthopnoea since 2 weeks. Cardiac examination revealed hypotension, tachycardia, pulsus paradoxus, jugular venous distension, muffled heart sounds, loud $\mathrm{P}_{2}$ and holosystolic murmur at left-lower sternal border. Transthoracic echocardiogram demonstrated a large circumferential pericardial effusion (PCE) with diastolic left atrial (LA) collapse and uncollapsed right atrium (RA; figures 1 and 2). Severe RA enlargement, severe tricuspid regurgitation, elevated right ventricular (RV) systolic pressure $(170 \mathrm{~mm} \mathrm{Hg})$ and dilated non-collapsible inferior vena cava were noted. RV demonstrated severe dilation and systolic dysfunction with paradoxical septal motion. Mitral valve demonstrated increased respiratory flow variation (figure 3). Urgent pigtail catheter

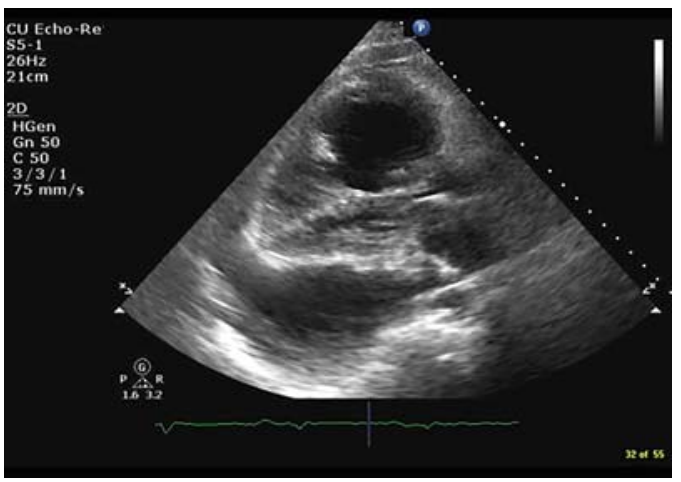

Figure 1 Transthoracic echocardiogram (parasternal long-axis view) showing left atrial and ventricular collapse as an atypical sign of cardiac tamponade.

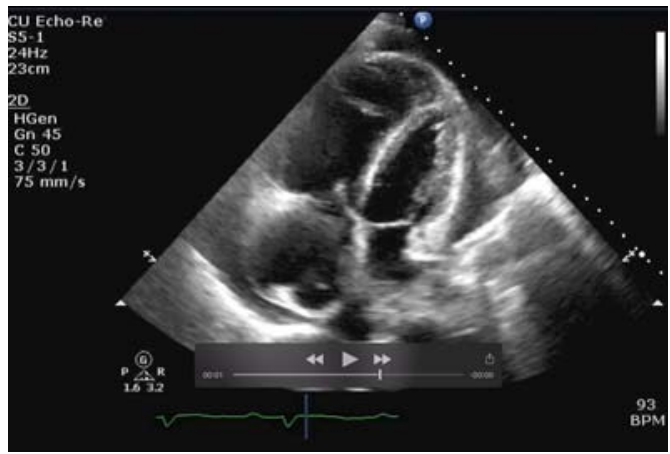

Figure 2 Transthoracic echocardiogram (apical four-chamber view) demonstrating systolic left atrial and ventricular collapse.

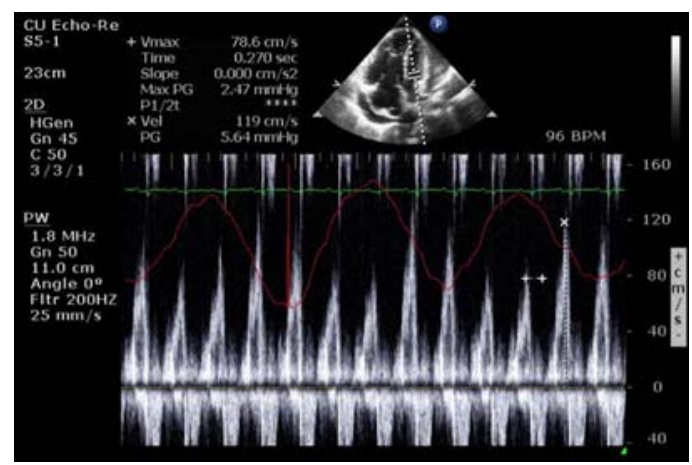

Figure 3 Transthoracic echocardiogram (apical four-chamber view) demonstrating respiratory variation in mitral inflow.

placement and drainage of $200 \mathrm{~mL}$ provided haemodynamic improvement. Gradual drainage of $2.3 \mathrm{~L}$ over 15 days was performed, with steady improvement in LA filling (figure 4). Serological and microbiological studies were unrevealing and the patient was referred for pulmonary rehabilitation, pending heart-lung transplantation.

In the setting of PAH, PCE is noted in 15-65\% and is an independent mortality predictor. ${ }^{1-3}$ PCE resulting in cardiac tamponade is noted only in $0.02 \%$ of PAH cases and causes significant haemodynamic and echocardiographic alterations due to high RA pressures. ${ }^{1}{ }^{3}{ }^{4}$ Postulated mechanism is venous/lymphatic obstruction with consequent cytokine release. ${ }^{2}{ }^{3}$ Atypical signs of tamponade include isolated LA/left ventricular collapse and increased respiratory variation of transmitral inflow. ${ }^{4}$ Rapid drainage has high peri-procedural mortality due to RV decompensation. ${ }^{2}{ }^{3}$ Gradual drainage, as in our patient, may be safer resulting in haemodynamic improvement. ${ }^{1}$

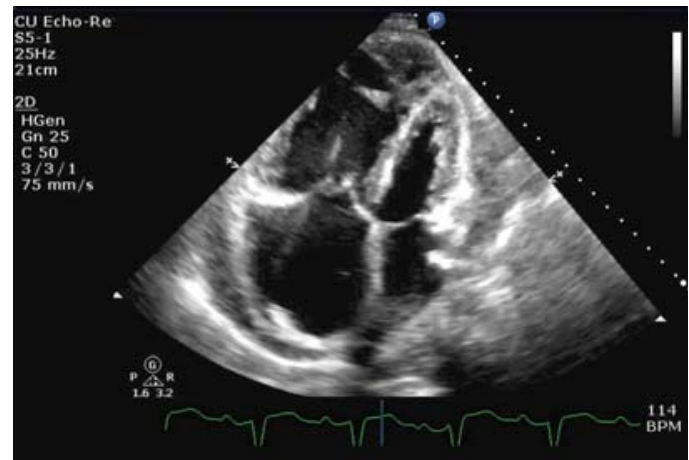

Figure 4 Transthoracic echocardiogram (apical four-chamber view) at discharge demonstrating improvement in left atrial volume. 


\section{Learning points}

- Pericardial effusion (PCE) in pulmonary artery hypertension (PAH) is rare and is an independent mortality predictor.

- Only $0.02 \%$ of patients with PAH have a significant PCE causing cardiac tamponade that frequently presents atypically due to elevated right-sided pressures.

- Gradual drainage of PCE is advantageous in conferring haemodynamic stability.

Acknowledgements The authors would like to thank Venkata M Alla, MD and Swapna Kanuri, MBBS from the Division of Cardiovascular Medicine, Creighton University School of Medicine for their critical evaluation and feedback on the manuscript.
Contributors SV contributed to evaluation of the patient, literature review, and drafting and finalising the manuscript. PRS contributed to evaluation of the patient and drafting of the manuscript.

Competing interests None.

Patient consent Obtained.

Provenance and peer review Not commissioned; externally peer reviewed.

\section{REFERENCES}

1 Fenstad ER, Le RJ, Sinak LJ, et al. Pericardial effusions in pulmonary arterial hypertension: characteristics, prognosis, and role of drainage. Chest 2013;144:1530-8.

2 Hemnes AR, Gaine SP, Wiener CM. Poor outcomes associated with drainage of pericardial effusions in patients with pulmonary arterial hypertension. South Med J 2008; 101:490-4.

3 Shimony A, Fox BD, Langleben $D$, et al. Incidence and significance of pericardial effusion in patients with pulmonary arterial hypertension. Can J Cardiol 2013;29:678-82.

4 Habib G, Torbicki A. The role of echocardiography in the diagnosis and management of patients with pulmonary hypertension. Eur Respir Rev 2010;19:288-99.

5 Honeycutt GR, Safdar Z. Pulmonary hypertension complicated by pericardial effusion: a single center experience. Ther Adv Respir Dis 2013;7:151-9.

Copyright 2015 BMJ Publishing Group. All rights reserved. For permission to reuse any of this content visit http://group.bmj.com/group/rights-licensing/permissions.

BMJ Case Report Fellows may re-use this article for personal use and teaching without any further permission.

Become a Fellow of BMJ Case Reports today and you can:

- Submit as many cases as you like

- Enjoy fast sympathetic peer review and rapid publication of accepted articles

- Access all the published articles

- Re-use any of the published material for personal use and teaching without further permission

For information on Institutional Fellowships contact consortiasales@bmjgroup.com

Visit casereports.bmj.com for more articles like this and to become a Fellow 